\title{
The Computational Fundamentals of Spatial Cycloidal Gearing
}

Giorgio FigLiolini, Università degli Studi di Cassino Hellmuth StaChel, Vienna University of Technology Jorge Angeles, McGill University, Montréal 


\section{Table of contents}

1. Introduction

2. Reuleaux's principle of gearing in the plane

3. Reuleaux's principle of gearing in 3-space

4. Consequences for skew gearing

5. Conclusion 


\section{Introduction}

WANTED: A gear set in order to transmit the rotary motion from wheel $\Sigma_{2}$ about axis $a_{21}$ to the second wheel $\Sigma_{3}$ with axis $a_{31}$ such that the ratio of angular velocities $\omega_{31} / \omega_{21}$ is constant.

spur gears

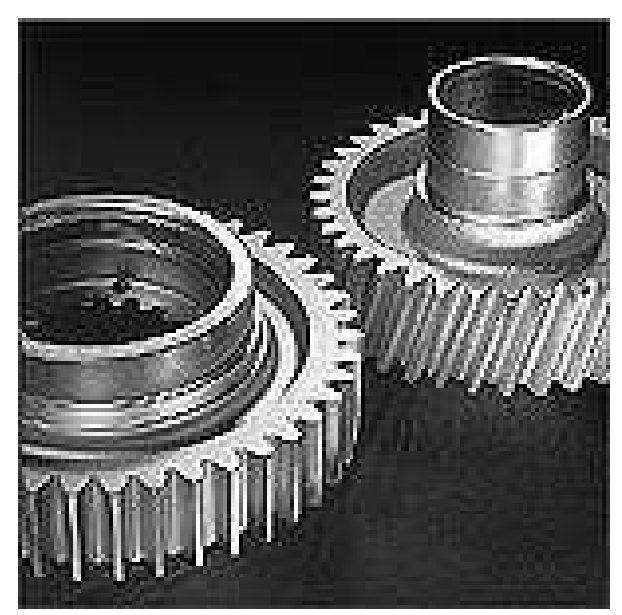

$a_{21}, a_{31}$ parallel bevel gears

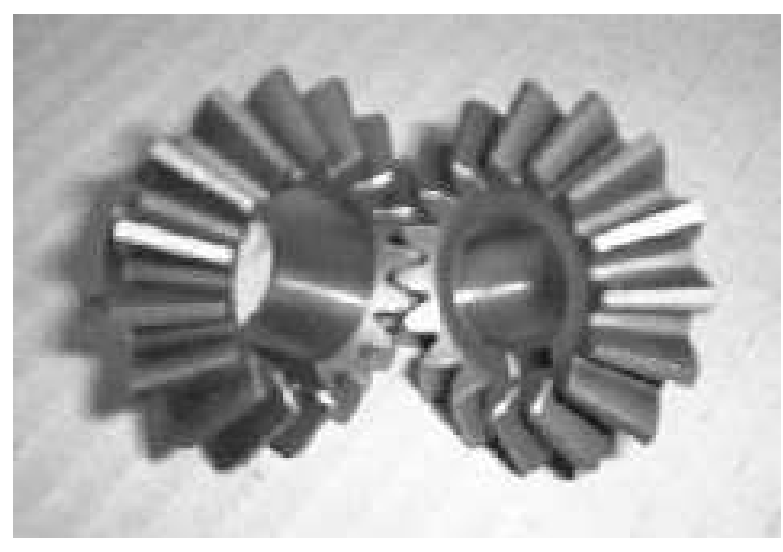

$a_{21}, a_{31}$ crossing skew gears

(e.g., worm gears)

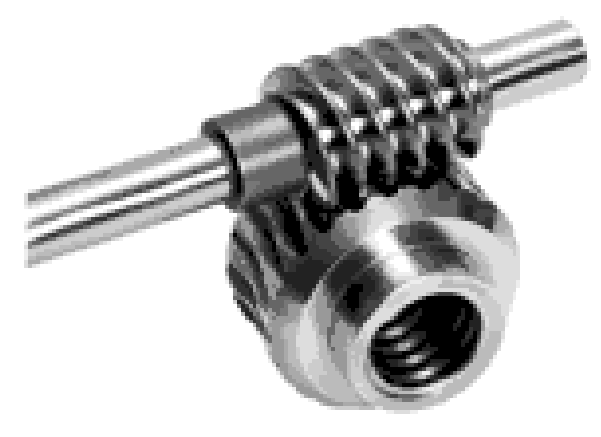

$a_{21}, a_{31}$ skew 


\section{Reuleaux's principle of gearing in the plane}

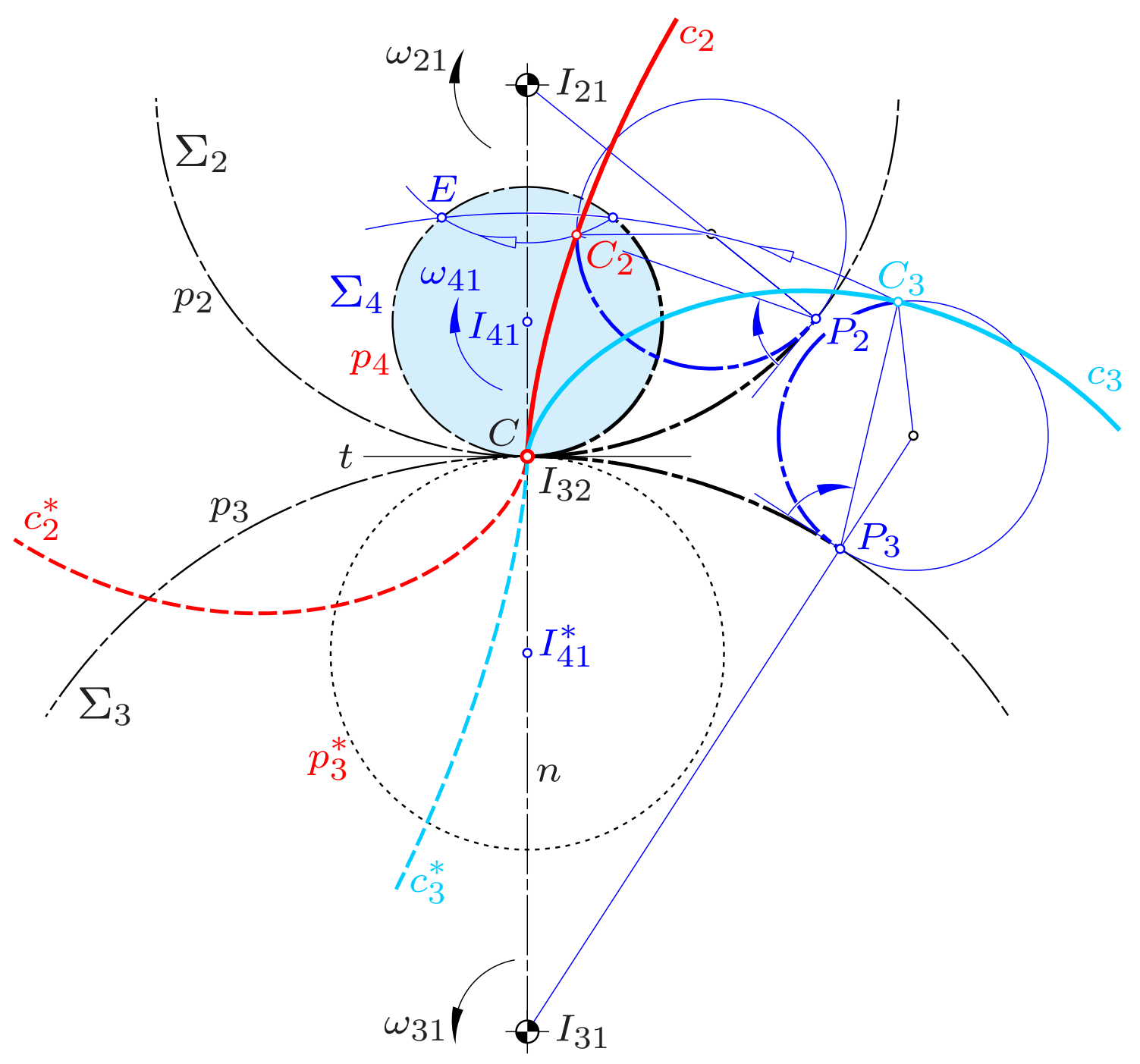

Principle of gearing by

? . . . Ch.E.L. Camus (1733),

F. Reuleaux (1875)

Let a smooth auxiliary curve $p_{4}$ roll on the polodes $p_{2}, p_{3}$. Then any point $C$ attached to $p_{4}$ traces conjugate tooth profiles $c_{2}, c_{3}$.

At cycloidal gears (see left) $p_{4}$ is a circle and $C \in p_{4}$. 


\section{Reuleaux's principle of gearing in the plane}

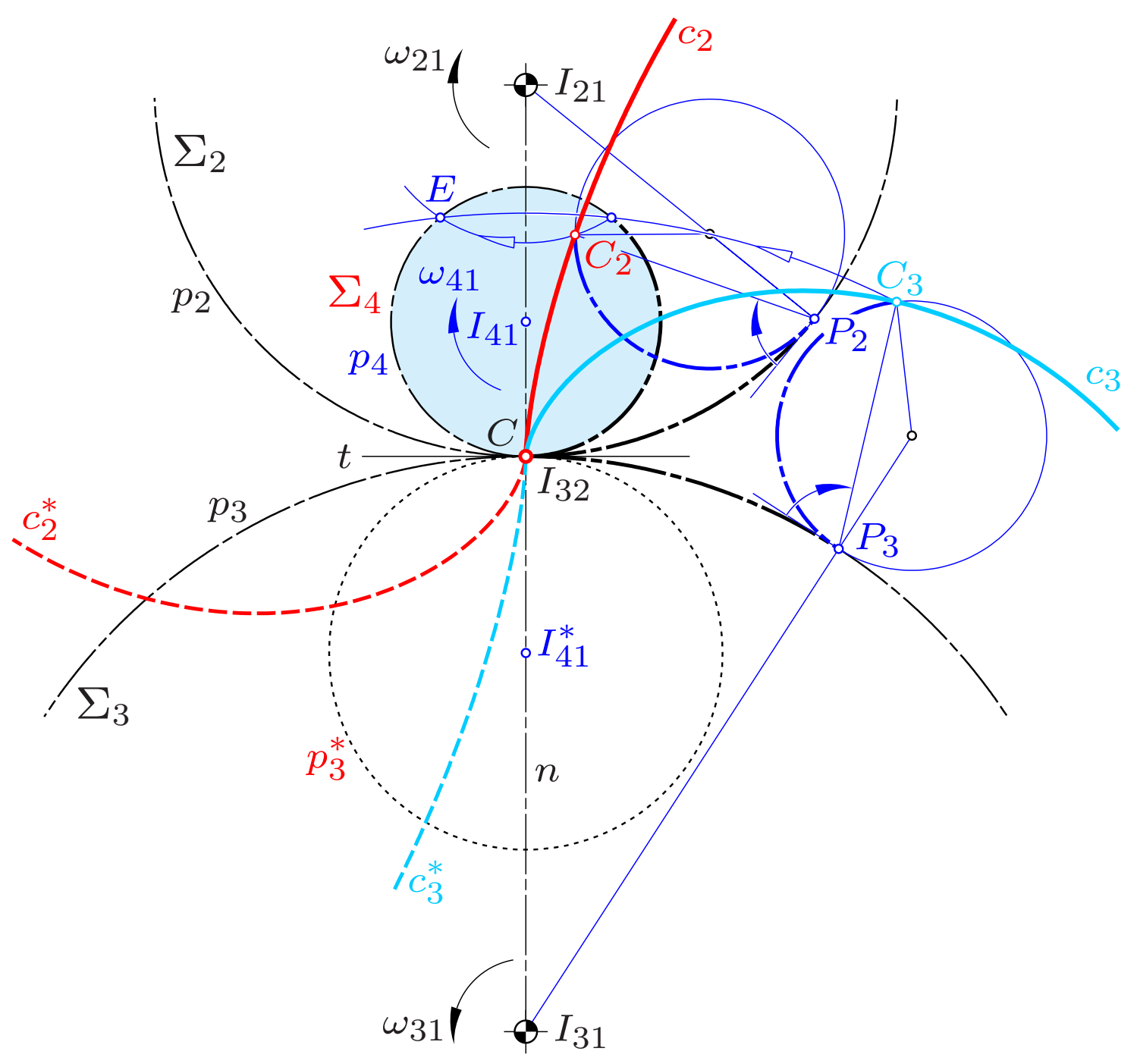

Adaption for 3D:

The auxiliary curve $p_{4}$ defines a system $\Sigma_{4}$ which can move such that for the relative poles holds: $I_{42}=I_{43}=I_{23}$. 


\section{Comments on Reuleaux's principle in the plane}

Almost all conjugate tooth profiles can be generated by Reuleaux's principle. E.g., for involute gearing the auxiliary curve is $p_{4} \subset \Sigma_{4}$ is a logarithmic spiral. 


\section{Comments on Reuleaux's principle in the plane}

Almost all conjugate tooth profiles can be generated by Reuleaux's principle. E.g., for involute gearing the auxiliary curve is $p_{4} \subset \Sigma_{4}$ is a logarithmic spiral.

\section{Generalization:}

Instead of a point $C \in \Sigma_{4}$ a smooth curve $c_{4} \subset \Sigma_{4}$ can be given. Then the envelopes $c_{2}, c_{3}$ of $c_{4}$ under $\Sigma_{4} / \Sigma_{2}$ and $\Sigma_{4} / \Sigma_{3}$, resp., give conjugate tooth flanks.

\section{Spherical kinematics:}

Reuleaux's principle is also valid in the spherical case, i.e., for bevel gears. 


\section{Reuleaux's principle of gearing in 3-space}

Given: Rotations $\Sigma_{2} / \Sigma_{1}, \Sigma_{3} / \Sigma_{1}$ about fixed skew axes $a_{21}, a_{31}$ with angular velocites $\omega_{21}, \omega_{31}$.

Question: Is there a frame $\Sigma_{4}$ moving such that the instantaneous screw motions of $\Sigma_{4} / \Sigma_{2}, \Sigma_{4} / \Sigma_{3}$ and $\Sigma_{3} / \Sigma_{2}$ are equal, i.e., equal axis and screw parameter, but different velocities. 


\section{Reuleaux's principle of gearing in 3-space}

Given: Rotations $\Sigma_{2} / \Sigma_{1}, \Sigma_{3} / \Sigma_{1}$ about fixed skew axes $a_{21}, a_{31}$ with angular velocites $\omega_{21}, \omega_{31}$.

Question: Is there a frame $\Sigma_{4}$ moving such that the instantaneous screw motions of $\Sigma_{4} / \Sigma_{2}, \Sigma_{4} / \Sigma_{3}$ and $\Sigma_{3} / \Sigma_{2}$ are equal, i.e., equal axis and screw parameter, but different velocities.

We find the answer by means of dual vectors. 


\section{Dual vectors in spatial kinematics}

bijection: $\quad$ Spear $g \mapsto$ dual unit vector $\widehat{\boldsymbol{g}}=\boldsymbol{g}+\varepsilon \boldsymbol{g}_{0}$ under $\varepsilon^{2}=0$, $\widehat{\boldsymbol{g}} \cdot \widehat{\boldsymbol{g}}=\boldsymbol{g} \cdot \boldsymbol{g}+2 \boldsymbol{g} \cdot \boldsymbol{g}_{0}=1+\varepsilon 0=1$. 


\section{Dual vectors in spatial kinematics}

bijection: $\quad$ Spear $g \mapsto$ dual unit vector $\widehat{\boldsymbol{g}}=\boldsymbol{g}+\varepsilon \boldsymbol{g}_{0}$ under $\varepsilon^{2}=0$, $\widehat{\boldsymbol{g}} \cdot \widehat{\boldsymbol{g}}=\boldsymbol{g} \cdot \boldsymbol{g}+2 \boldsymbol{g} \cdot \boldsymbol{g}_{0}=1+\varepsilon 0=1$.

$\widehat{\varphi}=\varphi+\varepsilon \varphi_{0}$ is called dual angle.

$\cos \widehat{\varphi}=\widehat{\boldsymbol{g}} \cdot \widehat{\boldsymbol{h}}=\boldsymbol{g} \cdot \boldsymbol{h}+\varepsilon\left(\boldsymbol{g}_{0} \cdot \boldsymbol{h}+\boldsymbol{g} \cdot \boldsymbol{h}_{0}\right)$,

$\sin \widehat{\varphi} \widehat{\boldsymbol{n}}=\widehat{\boldsymbol{g}} \times \widehat{\boldsymbol{h}}=$

$=\boldsymbol{g} \times \boldsymbol{h}+\varepsilon\left[\left(\boldsymbol{g}_{0} \times \boldsymbol{h}\right)+\left(\boldsymbol{g} \times \boldsymbol{h}_{0}\right)\right]$.

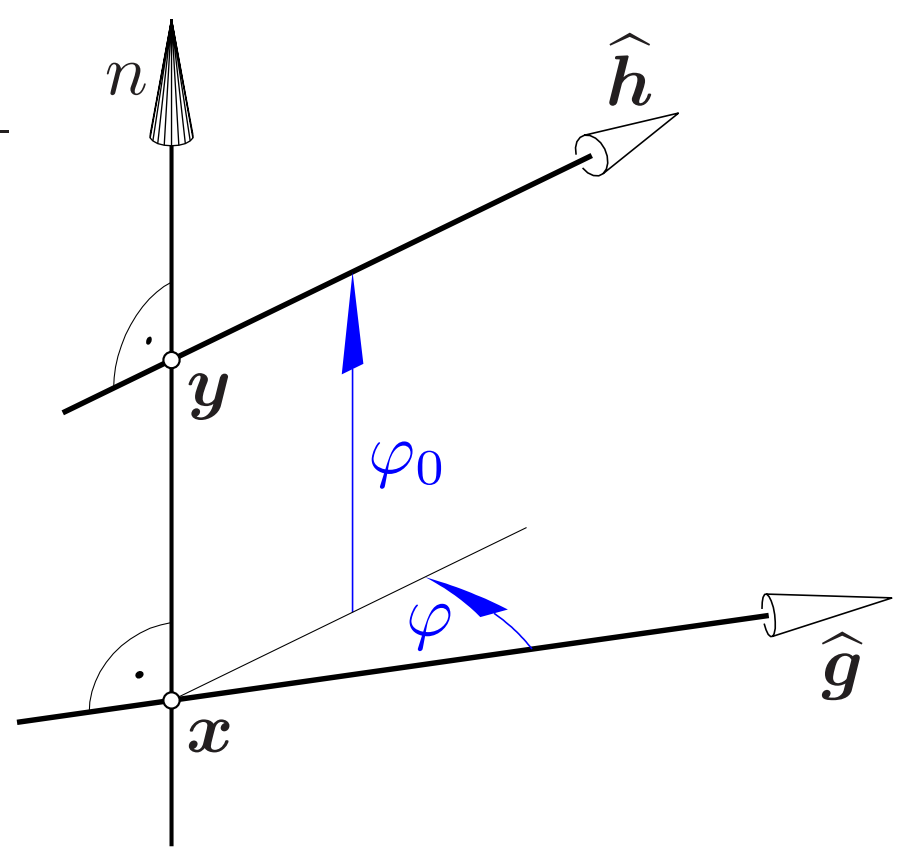




\section{Dual vectors in spatial kinematics}

Bijection: Instantaneous motion of $\Sigma_{i} / \Sigma_{j} \mapsto$ twist $\widehat{\boldsymbol{q}}_{i j}=\widehat{\omega}_{i j} \widehat{\boldsymbol{p}}_{i j}$ with $\widehat{\boldsymbol{p}}_{i j}$ as spear of the instantaneous axis and $\widehat{\omega}_{i j}=\omega_{i j}+\varepsilon \omega_{i j 0}$ with $\omega_{i j}$ and $\omega_{i j 0}$ as instantaneous angular- and translatory velocity, respectively. 


\section{Dual vectors in spatial kinematics}

Bijection: Instantaneous motion of $\Sigma_{i} / \Sigma_{j} \mapsto$ twist $\widehat{\boldsymbol{q}}_{i j}=\widehat{\omega}_{i j} \widehat{\boldsymbol{p}}_{i j}$ with $\widehat{\boldsymbol{p}}_{i j}$ as spear of the instantaneous axis and $\widehat{\omega}_{i j}=\omega_{i j}+\varepsilon \omega_{i j 0}$ with $\omega_{i j}$ and $\omega_{i j 0}$ as instantaneous angular- and translatory velocity, respectively.

Aronhold-Kennedy Theorem:

Given: $\Sigma_{1}, \Sigma_{2}, \Sigma_{3}$ and instantaneous twists $\widehat{\boldsymbol{q}}_{21}, \widehat{\boldsymbol{q}}_{31}$ of $\Sigma_{2} / \Sigma_{1}, \Sigma_{3} / \Sigma_{1}$, resp.,

$\Longrightarrow \widehat{\boldsymbol{q}}_{32}=\widehat{\boldsymbol{q}}_{31}-\widehat{\boldsymbol{q}}_{21}$ is the twist of the relative motion $\Sigma_{3} / \Sigma_{2}$. 


\section{Plücker's conoid}

Let $\Sigma_{2}$ and $\Sigma_{3}$ rotate about fixed skew axes $\widehat{\boldsymbol{p}}_{21}, \widehat{\boldsymbol{p}}_{31}$ with variable angular velocities $\omega_{21}, \omega_{31}$, respectively.

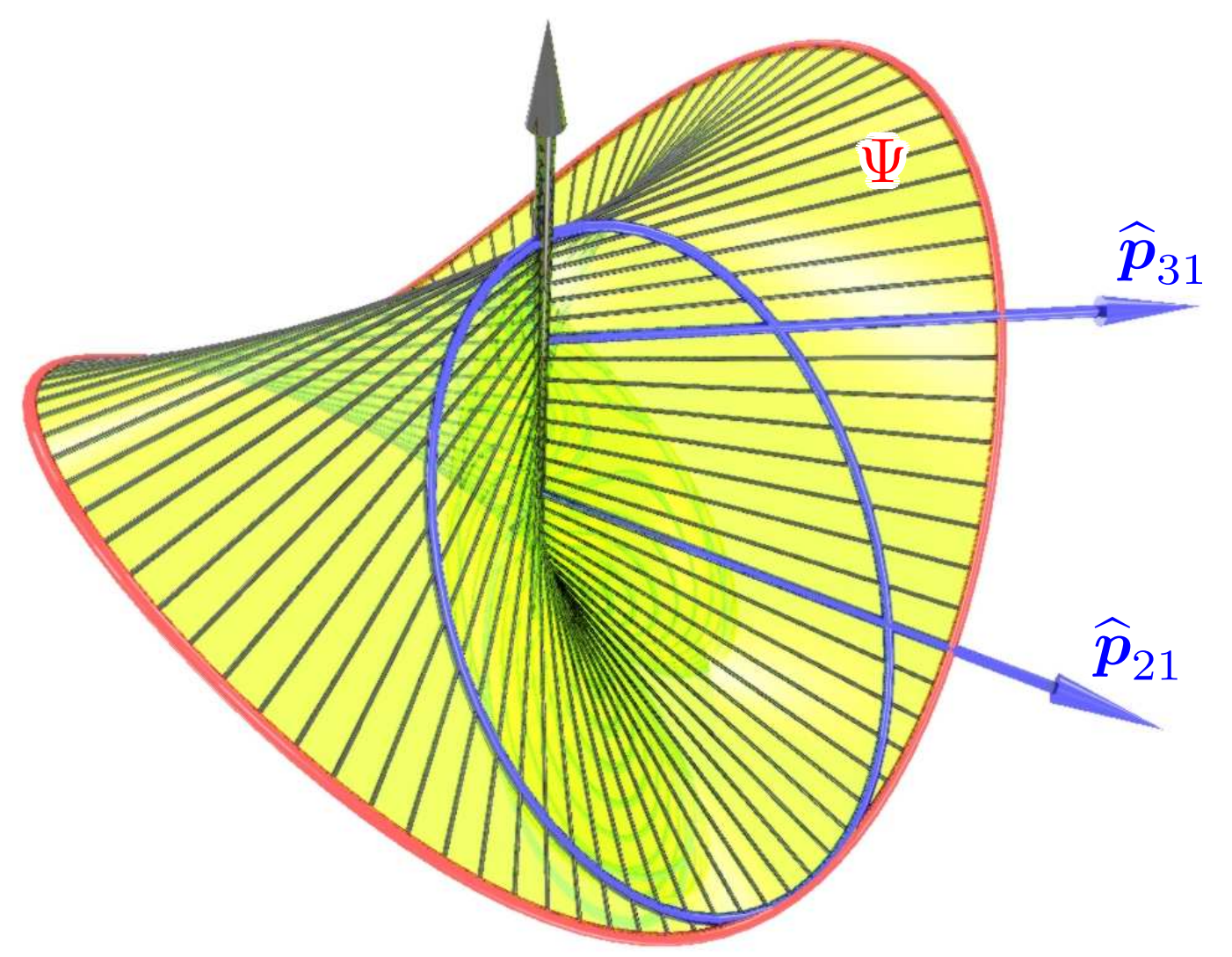

Then in any case the twist

$$
\widehat{\omega}_{32} \widehat{\boldsymbol{p}}_{32}=\omega_{31} \widehat{\boldsymbol{p}}_{31}-\omega_{21} \widehat{\boldsymbol{p}}_{21}
$$

is a real linear combination of $\widehat{\boldsymbol{p}}_{21}$ and $\widehat{\boldsymbol{p}}_{31} \Longrightarrow$

$\widehat{\boldsymbol{p}}_{32}$ is located on Plücker's conoid $\Psi$ (=cylindroid).

The position of $\widehat{p}_{32}$ on $\Psi$ defines the pitch $h_{32}=$ $\omega_{320} / \omega_{32}$ uniquely. 


\section{Reuleaux's principle of gearing in 3-space}

Given: Rotations $\Sigma_{2} / \Sigma_{1}, \Sigma_{3} / \Sigma_{1}$ about fixed skew axes $\widehat{\boldsymbol{p}}_{21}, \widehat{\boldsymbol{p}}_{31}$ with angular velocites $\omega_{21}, \omega_{31}$.

Question: Is there a frame $\Sigma_{4}$ moving such that the instantaneous screw motions of $\Sigma_{4} / \Sigma_{2}, \Sigma_{4} / \Sigma_{3}$ and $\Sigma_{3} / \Sigma_{2}$ are equal, i.e., equal axis and screw parameter, but different velocities. 


\section{Reuleaux's principle of gearing in 3-space}

Given: Rotations $\Sigma_{2} / \Sigma_{1}, \Sigma_{3} / \Sigma_{1}$ about fixed skew axes $\widehat{\boldsymbol{p}}_{21}, \widehat{\boldsymbol{p}}_{31}$ with angular velocites $\omega_{21}, \omega_{31}$.

Question: Is there a frame $\Sigma_{4}$ moving such that the instantaneous screw motions of $\Sigma_{4} / \Sigma_{2}, \Sigma_{4} / \Sigma_{3}$ and $\Sigma_{3} / \Sigma_{2}$ are equal, i.e., equal axis and screw parameter, but different velocities.

$$
\begin{gathered}
\widehat{\boldsymbol{q}}_{42}=\lambda_{2} \widehat{\boldsymbol{q}}_{32}, \quad \widehat{\boldsymbol{q}}_{43}=\lambda_{3} \widehat{\boldsymbol{q}}_{32}, \quad \lambda_{1}, \lambda_{2} \in \mathbb{R}, \Longrightarrow \widehat{\boldsymbol{q}}_{41}-\widehat{\boldsymbol{q}}_{i 1}=\lambda_{i}\left(\widehat{\boldsymbol{q}}_{31}-\widehat{\boldsymbol{q}}_{21}\right), \\
\widehat{\boldsymbol{q}}_{41}=\lambda_{1} \widehat{\boldsymbol{q}}_{31}+\left(1-\lambda_{1}\right) \widehat{\boldsymbol{q}}_{21}=\left(1+\lambda_{2}\right) \widehat{\boldsymbol{q}}_{31}-\lambda_{2} \widehat{\boldsymbol{q}}_{21}
\end{gathered}
$$

Necessary and sufficient: The instantaneous axes $\widehat{\boldsymbol{p}}_{41}$ of $\Sigma_{4} / \Sigma_{1}$ are located on Plücker's conoid $\Psi$ and the pitch $h_{41}$ is corresponding to this position. 


\section{A tribute to Martin DISTELI}

M. Disteli: Über die Verzahnung der Hyperboloidräder mit geradlinigem Eingriff.

Z. Math. Phys. 59, 244-298 (1911)

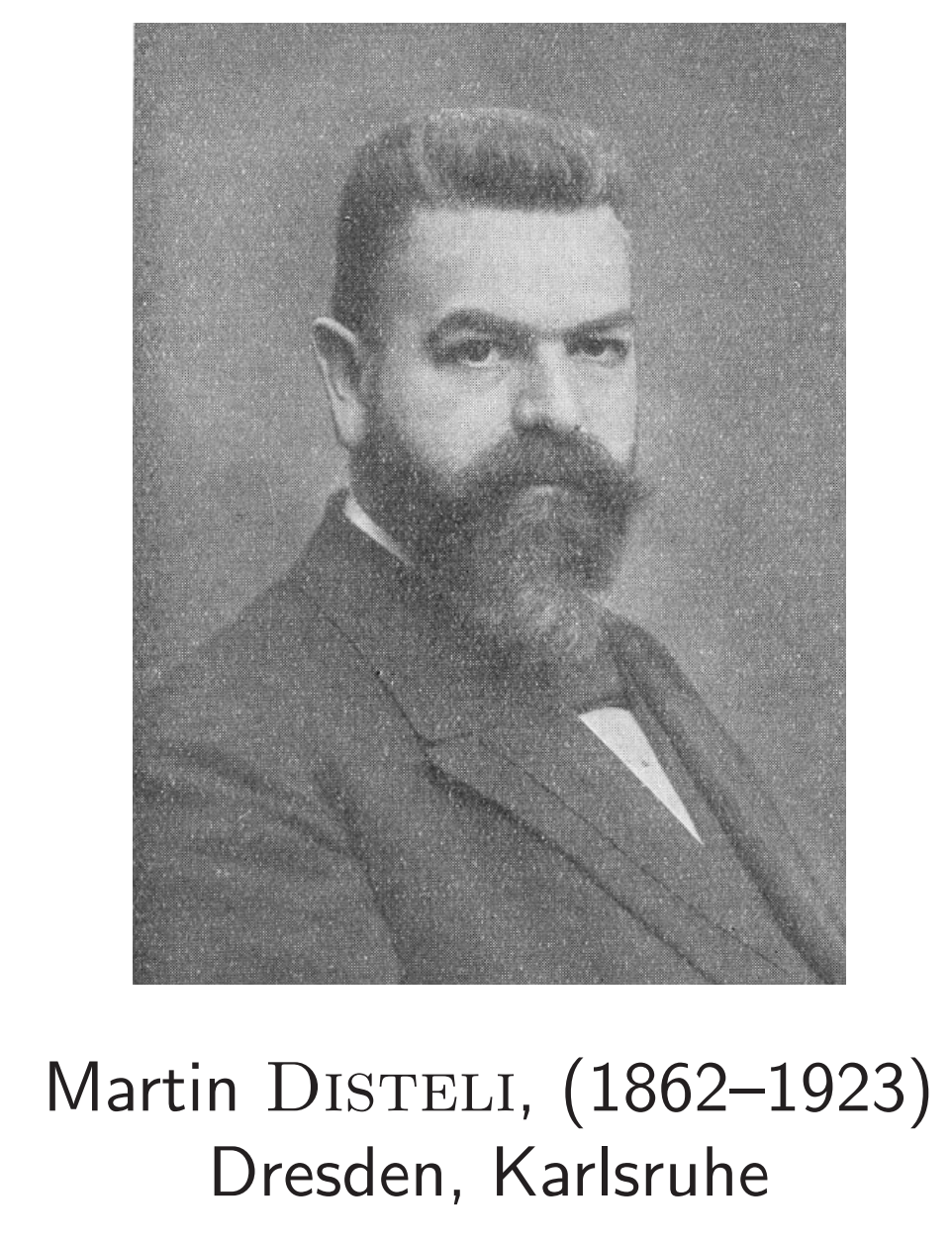




\section{Schriftenverzeichnis.}

1. Die Steinerschen Schließungsprobleme nach darstellend-geometrischer Methode. Inaug.-Diss. Zürich 1888.

2. Zur Konfiguration der Wendepunkte der allgemeinen ebenen Kurve dritter Ordnung. Vierteljahrsschrift der Züricher Naturf.-Ges. XXXV, 1890.

3. Die Metrik der zirkularen ebenen Kurven dritter Ordnung im Zusammenhange mit geometrischen Lehrsätzen Jakob Steiners. Ebenda XXXVII, 1891.

4. Über Stellen innigster Berührung einer ebenen dritter Ordnung mit einer ebenen Kurve $n$-ter Ordnung. Zeitschr. f. Math. u. Phys. 38, 1893.

5. Über Rollkurven und Rollflächen. Ebenda 43, 1898.

6. Über Rollkurven und Rollflächen. Ebenda 46, 1901.

7. Über instantane Schraubengeschwindigkeiten und die Verzahnung der Hyperboloidräder. Ebenda 51, 1904.

8. Über einige Sätze der kinematischen Geometrie, welche der Verzahnungslehre zylindrischer und konischer Räder zugrunde liegen. Ebenda 56, 1908.

9. Über die Verzahnung der Hyperboloidräder mit geradlinigem Eingriff. Ebenda 59, 1911.

10. Über das Analogon der Savaryschen Formel und Konstruktion in der kinematischen Geometrie des Raumes. Ebenda 62, 1913. 
Arbeiten die Axoide erledigt, so gilt es weiter die Verzahnung der zugehörigen Räderpaare durchzuführen. Dies geschieht in den folgenden Abhạndlungen im Anschlusse an die Ballsche Schraubentheorie. Wir können in Rücksicht auf den uns zugemessenen Raum schon deshalb nicht auf Einzelheiten eingehen, weil die Darstellung hier vielfach insofern nicht ganz glücklich ist, als bei der Zusammenfassung der schönen und neuen Resultate die darin vorkommenden Gebilde nur durch Buchstaben bezeichnet werden, deren Bedeutung oft auf einer verwickelten Erklärung beruht. Es wäre wünschenswert, wenn diese Teile einer verständlicheren Bearbeitung unterzogen würden. Wir bemerken zum Schlusse nur noch, daB in der letzten Schrift die sogenannte Savary sche Formel der ebenen Bewegungslehre, welche den augenblicklichen Krümmungskreis der Bahnkurve irgendeines Punktes des bewegten Systems zu bestimmen erlaubt, falls die augenblicklichen Krümmungskreise der beiden Polbahnen bekannt sind, auf die hier in Betracht kommenden räumlichen Bewegungen ausgedehnt werden. An die Stelle des Krümmungskreises tritt dann die augenblickliche Striktionsschraubenfläche der Axoide. Gerade in der Behandlung der zuletzt skizzierten Probleme zeigte sich Distelis besondere Stärke. 


\section{Inhalt.}

Seito

Beyel, Christian. Über den Rechenschieber, insbesondere den von Pozzi . 369

Blasius, H. Träger kleinster Durchbiegung und Stäbe größter Knickfestigkeit bei gegebenem Materialverbrauch . . . . . . . . . . . . . 182

Blumenthal, 0tto. Utber asymptotische Integration von Differentialgleichungen mit Anwendung auf die Berechnung von Spannungen in Kugelschalen Über die Genauigkeit der Wurzeln linearer Gleichungen. . . . . . .

Disteli, Martin. Über das Analogon der Savaryschen Formel und Konstruk-. tion in der kinematischen Geometrie des Raumes . . . . . . . . . . 261

Einstein, Albert und Großmann, Marcel. Entwurf einer verallgemeinerten Relativitätstheorie und einer Theorie der Gravitation . . . . . . . 225

I. Physikalischer Teil. Von Albert Einstein. . . . . . . . . . . 225

II. Mathematischer Teil. Von Marcel GroBmann . . . . . . . . . . . 244

Federhofer, Karl. Berechnung des senkrecht zu seiner Ebene belasteten

Bogenträgers. . . . . . . . . . . . . . . . 440 


\section{Consequences for skew gearing}

In analogy to cycloid gearing in the plane, we specify the axis $\widehat{p}_{41}$ of $\Sigma_{4} / \Sigma_{1}$ on Plücker's conoid and keep it fixed in the machine frame $\Sigma_{1}$.

Then we move simultaneously $\Sigma_{2}$ with the twist $\widehat{\boldsymbol{q}}_{21}, \Sigma_{3}$ with twist $\widehat{\boldsymbol{q}}_{31}$ and $\Sigma_{4}$ with twist $\widehat{\boldsymbol{q}}_{41}$ (axis $\widehat{\boldsymbol{p}}_{41}$ and pitch $h_{41}$ ) such that the relative axes $\widehat{\boldsymbol{p}}_{42}, \widehat{\boldsymbol{p}}_{43}$ and $\widehat{p}_{32}$ coincide. 


\section{Consequences for skew gearing}

In analogy to cycloid gearing in the plane, we specify the axis $\widehat{p}_{41}$ of $\Sigma_{4} / \Sigma_{1}$ on Plücker's conoid and keep it fixed in the machine frame $\Sigma_{1}$.

Then we move simultaneously $\Sigma_{2}$ with the twist $\widehat{\boldsymbol{q}}_{21}, \Sigma_{3}$ with twist $\widehat{\boldsymbol{q}}_{31}$ and $\Sigma_{4}$ with twist $\widehat{\boldsymbol{q}}_{41}$ (axis $\widehat{\boldsymbol{p}}_{41}$ and pitch $h_{41}$ ) such that the relative axes $\widehat{\boldsymbol{p}}_{42}, \widehat{\boldsymbol{p}}_{43}$ and $\widehat{p}_{32}$ coincide.

Main Theorem: For each line $\widehat{\boldsymbol{g}}$ attached to $\Sigma_{4}$ the ruled surfaces $\Phi_{2}, \Phi_{3}$ traced by $\widehat{\boldsymbol{g}}$ under $\Sigma_{4} / \Sigma_{2}$ and $\Sigma_{4} / \Sigma_{3}$, resp., are conjugate tooth flanks.

The contact takes place at of points of $\widehat{\boldsymbol{g}}$. 


\section{Consequences for skew gearing}

Proof: The distribution of tangent planes of $\Phi_{2}$ and $\Phi_{3}$ along the line $\widehat{\boldsymbol{g}}$ is defined by the derivatives $\dot{\hat{\boldsymbol{g}}}$, i.e., by

$$
\Sigma_{4} / \Sigma_{2}: \dot{\hat{\boldsymbol{g}}}=\widehat{\boldsymbol{g}} \times \widehat{\boldsymbol{q}}_{42}, \quad \Sigma_{4} / \Sigma_{3}: \dot{\hat{\boldsymbol{g}}}=\widehat{\boldsymbol{g}} \times \widehat{\boldsymbol{q}}_{43} .
$$

Since $\widehat{\boldsymbol{q}}_{42}$ and $\widehat{\boldsymbol{q}}_{43}$ are real multiples of $\widehat{\boldsymbol{q}}_{32}$, the same holds for $\dot{\hat{\boldsymbol{g}}}$. They have the same distribution of tangent planes. 


\section{Consequences for skew gearing}

Proof: The distribution of tangent planes of $\Phi_{2}$ and $\Phi_{3}$ along the line $\widehat{\boldsymbol{g}}$ is defined by the derivatives $\dot{\hat{\boldsymbol{g}}}$, i.e., by

$$
\Sigma_{4} / \Sigma_{2}: \dot{\hat{\boldsymbol{g}}}=\widehat{\boldsymbol{g}} \times \widehat{\boldsymbol{q}}_{42}, \quad \Sigma_{4} / \Sigma_{3}: \dot{\hat{\boldsymbol{g}}}=\widehat{\boldsymbol{g}} \times \widehat{\boldsymbol{q}}_{43} .
$$

Since $\widehat{\boldsymbol{q}}_{42}$ and $\widehat{\boldsymbol{q}}_{43}$ are real multiples of $\widehat{\boldsymbol{q}}_{32}$, the same holds for $\dot{\hat{\boldsymbol{g}}}$. They have the same distribution of tangent planes.

The axodes of $\Sigma_{3} / \Sigma_{2}$ are one-sheet hyperboloids of revolution $\Pi_{2}, \Pi_{3}$.

Under $\Sigma_{4} / \Sigma_{2}$ and $\Sigma_{4} / \Sigma_{3}$ a ruled helical surface $\Pi_{4}$ (auxiliary surface) is sliding and rolling (German: schroten) along the hyperboloids.

In analogy to planar are spherical cycloidal gearing we start with the generator $\widehat{\boldsymbol{g}}=\widehat{\boldsymbol{p}}_{32}=\mathrm{ISA}$. 


\section{Consequences for skew gearing}

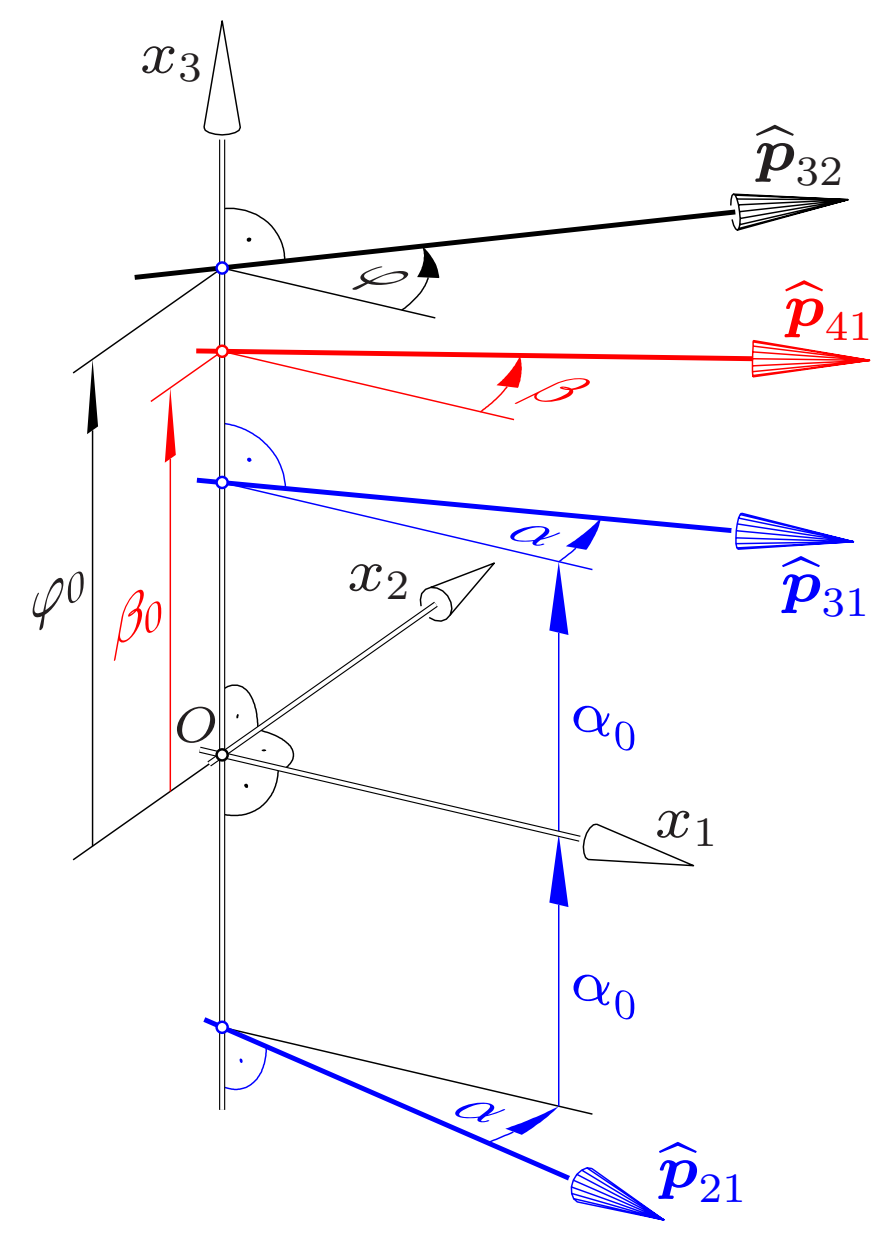

There are 4 axes involved - all located on Plücker's conoid

- Axes $\widehat{\boldsymbol{p}}_{21}, \widehat{\boldsymbol{p}}_{31}$ of the wheels,

- the ISA $\widehat{p}_{32}$, and

- the axis $\widehat{p}_{41}$ of the auxiliary system $\Sigma_{4}$. 


\section{Consequences for skew gearing}

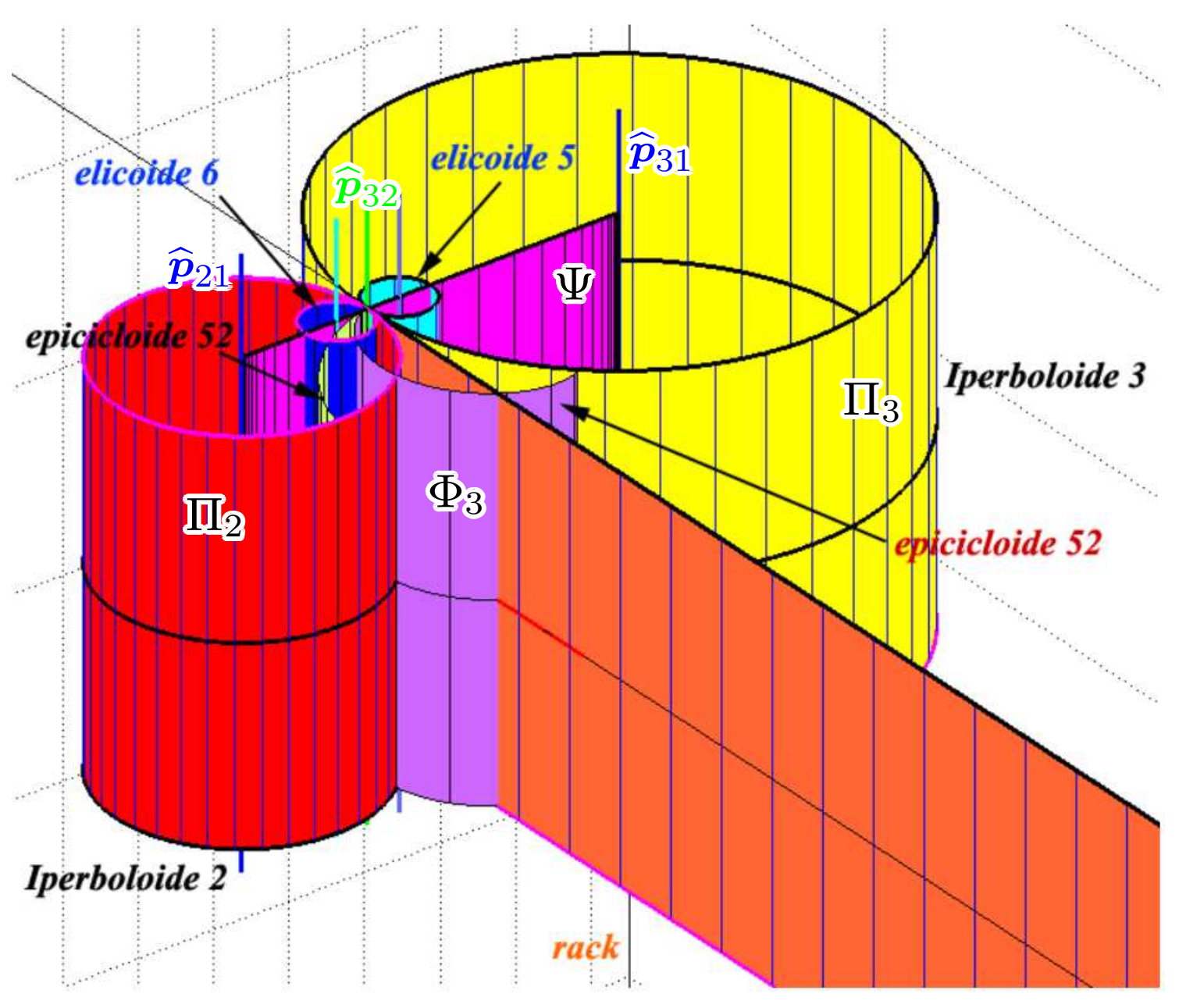

planar case 


\section{Consequences for skew gearing}

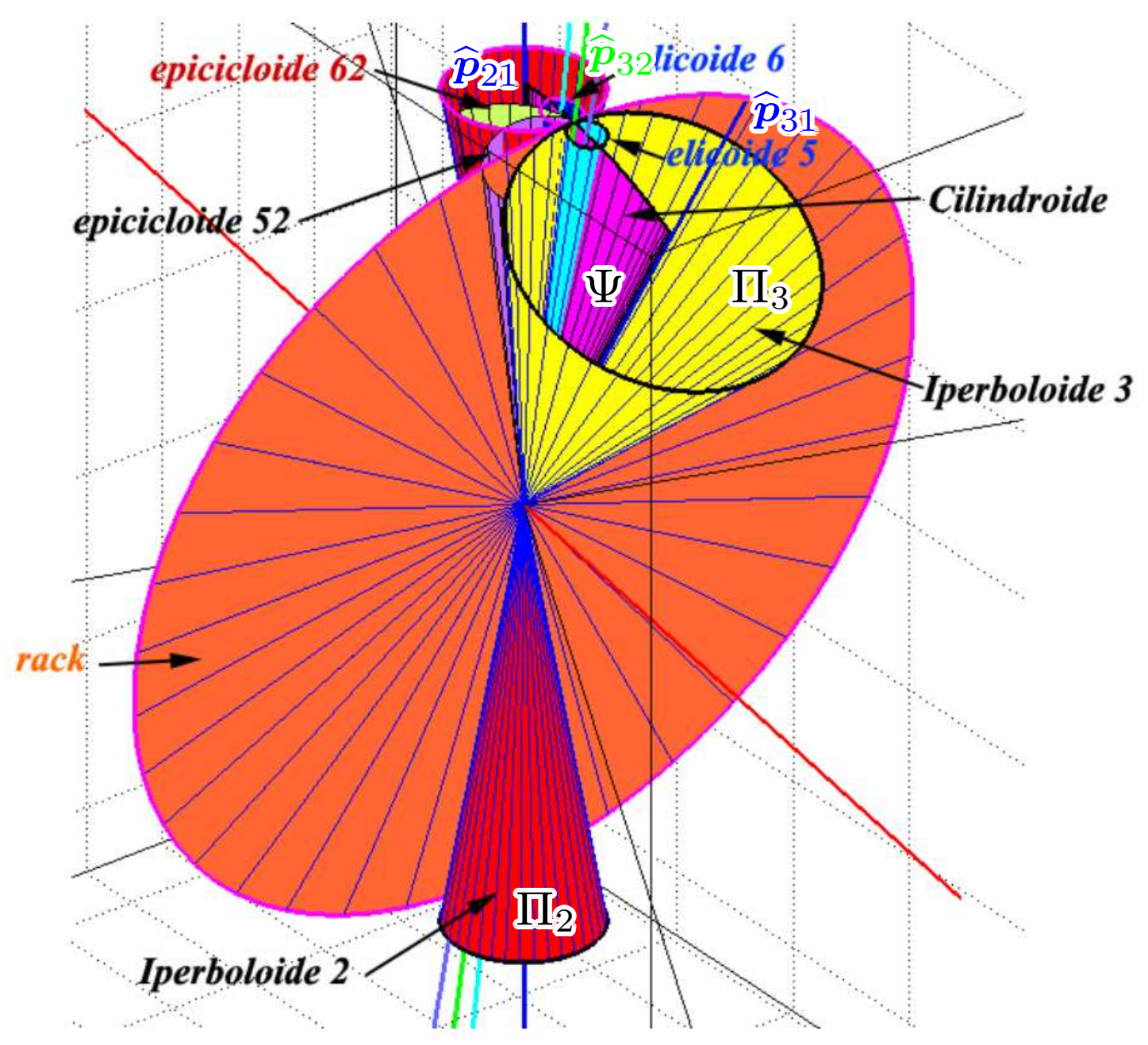

spherical case 


\section{Consequences for skew gearing}

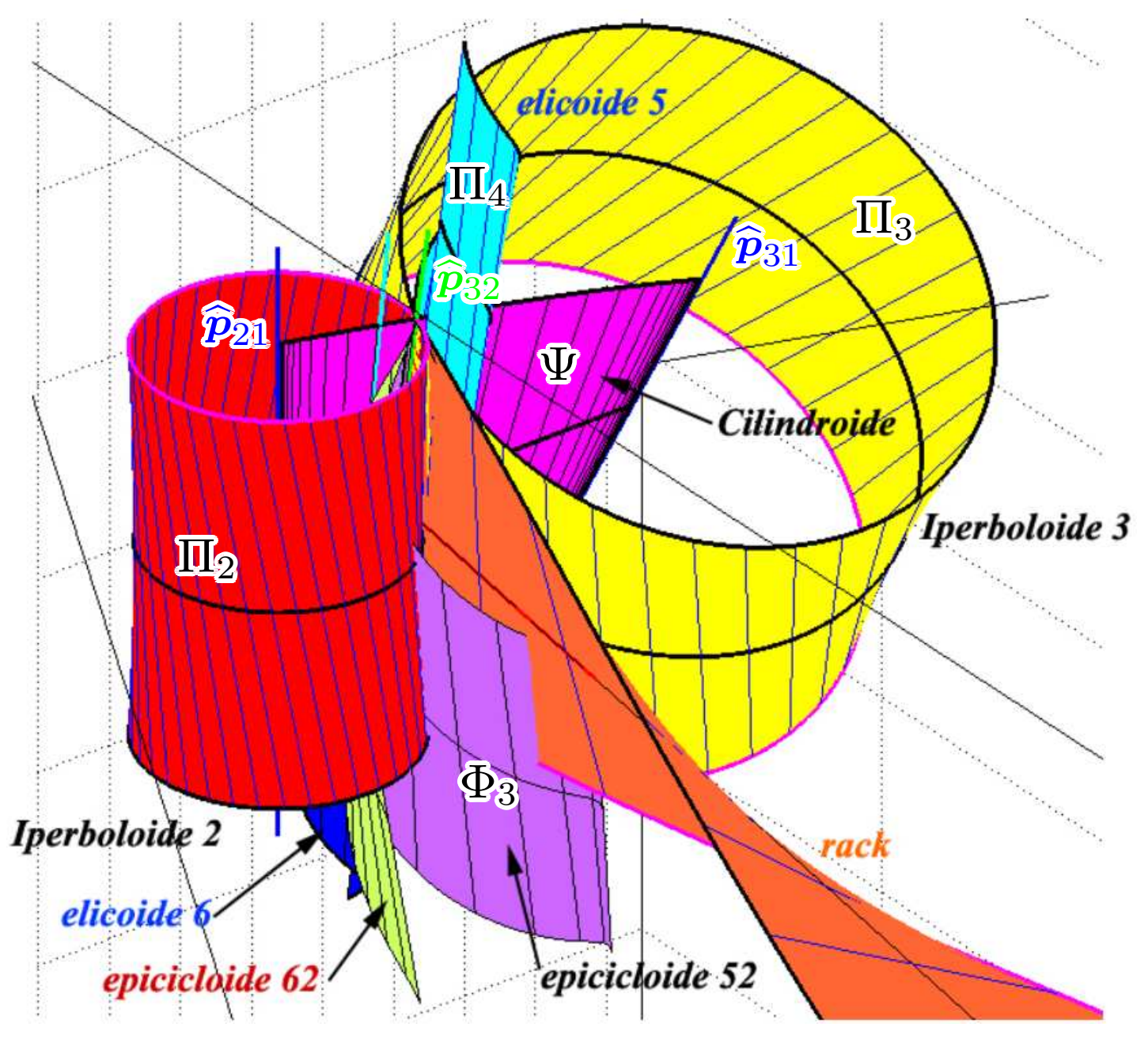

skew case 


\section{Consequences for skew gearing}
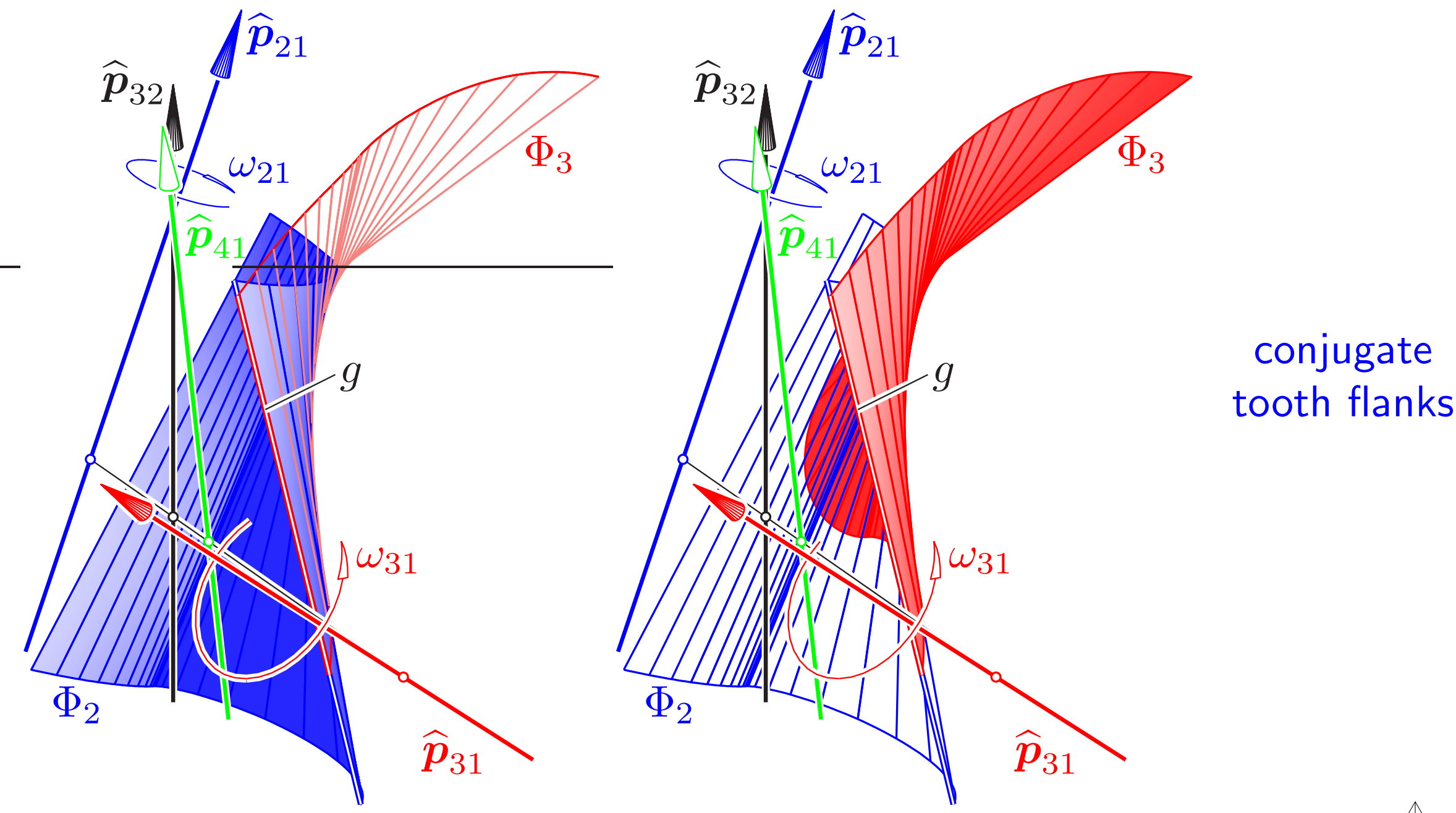


\section{Consequences for skew gearing}




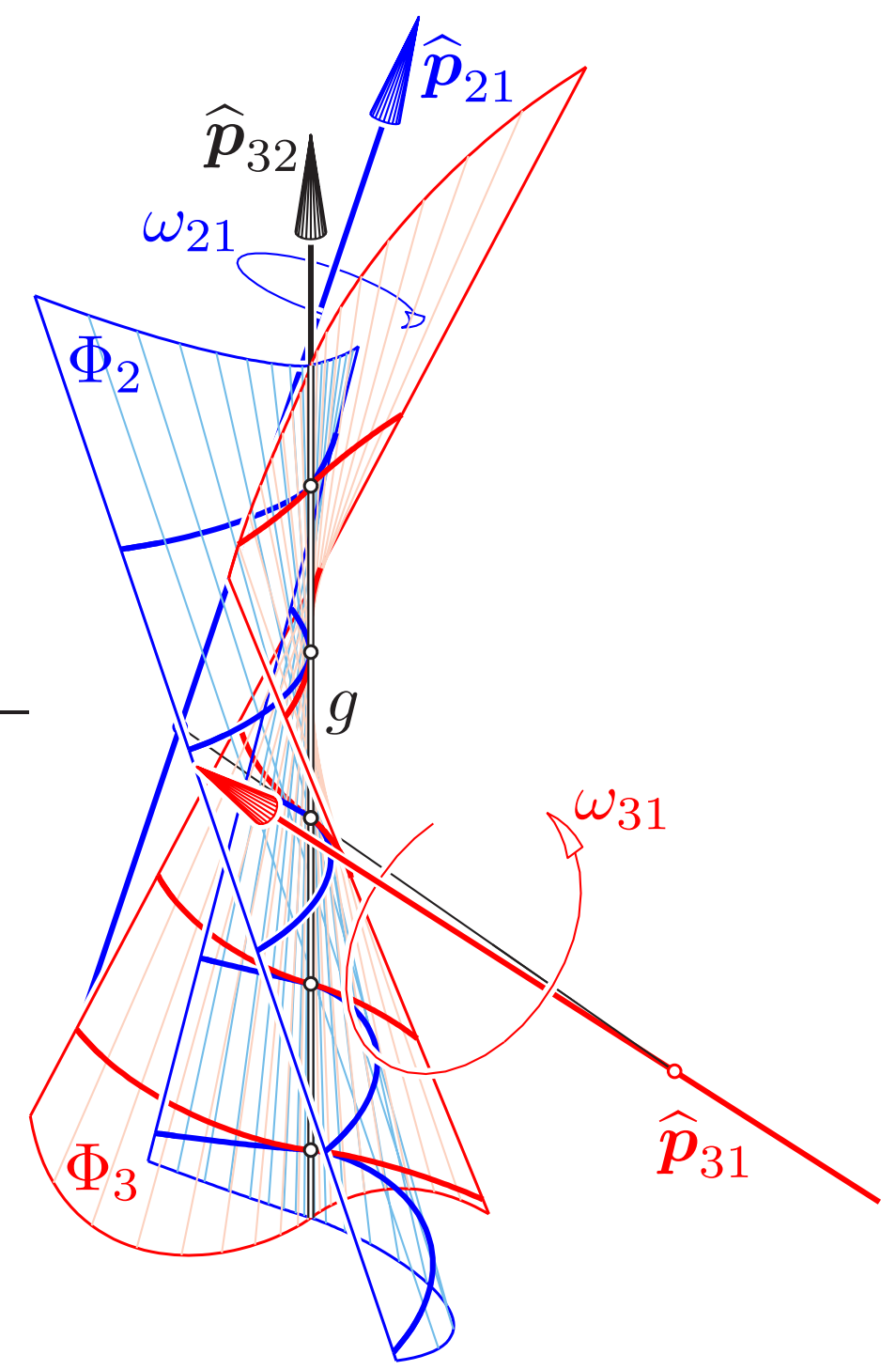

These are conjugate cycloidal tooth flanks $\Phi_{2}, \Phi_{3}$.

The displayed red and blue curves are the intersections with planes orthogonal to the line $g$ of contact.

In this particular case $g$ is the ISA and therefore a singular line of the ruled surface - like a cusp in the plane.

Each tooth flank is composed from two parts glued together along $g$. In can be proved that such pairs of surfaces have a common tangent plane at each point of $g$. 


\section{Consequences for skew gearing}

Theorem: For each surface $\Phi_{4}$ attached to $\Sigma_{4}$ the envelopes $\Phi_{2}, \Phi_{3}$ of under $\Sigma_{4} / \Sigma_{2}$ and $\Sigma_{4} / \Sigma_{3}$, resp., are conjugate tooth flanks. 


\section{Consequences for skew gearing}

Theorem: For each surface $\Phi_{4}$ attached to $\Sigma_{4}$ the envelopes $\Phi_{2}, \Phi_{3}$ of under $\Sigma_{4} / \Sigma_{2}$ and $\Sigma_{4} / \Sigma_{3}$, resp., are conjugate tooth flanks.

Proof: For any pose of $\Phi_{4}$, a point $C$ is a point of contact between $\Phi_{4}$ and its envelope $\Phi_{i}$ under $\Sigma_{4} / \Sigma_{i}, i=2,3$, if and only if the surface normal $\widehat{n}$ of $\Phi_{4}$ at $C$ belongs to the linear line complex

$$
\boldsymbol{q}_{4 i 0} \cdot \boldsymbol{n}+\boldsymbol{q}_{4 i} \cdot \boldsymbol{n}_{0}=0
$$

Twists differing by a real factor define the same linear line complex. 


\section{Conclusions}

The main goal of this paper is to shed light on the geometry of the tooth flanks of gears with skew axes.

To this end, the authors follow and extend results reported by Martin DisTELI, thereby deriving ruled surfaces as conjugate tooth flanks in contact along a line. 


\section{Conclusions}

The main goal of this paper is to shed light on the geometry of the tooth flanks of gears with skew axes.

To this end, the authors follow and extend results reported by Martin DisTELI, thereby deriving ruled surfaces as conjugate tooth flanks in contact along a line.

A detailed analysis of the tooth flanks obtained for constant and for variable axis $\widehat{\boldsymbol{p}}_{41} \in \Psi$ is left for future research.

Conjecture: Any pair of conjugate ruled tooth flanks with contact along lines can be obtained by this principle. 


\section{References}

- J. Angeles: The Application of Dual Algebra to Kinematic Analysis. In J. Angeles, E. Zakhariev (eds.): Computational Methods in Mechanical Systems, Springer-Verlag, Heidelberg 1998, Vol. 161, pp. 3-31.

- G. Figliolini, H. Stachel, J. Angeles: A new look at the Ball-Disteli diagram and its relevance to spatial gearing. Mech. Mach. Theory 42/10, 1362-1375 (2007).

- C. Huang, P.-C. Liu, S.-C. Hung: Tooth contact analysis of the general spatial involute gearing. Proceedings $12^{\text {th }}$ IFToMM World Congress, Besançon/France, 2007, paper no. 836.

- M. Husty, A. Karger, H. Sachs, W. Steinhilper:

Kinematik und Robotik. Springer- Verlag, Berlin Heidelberg 1997. 
- F.L. Litvin, A. Fuentes: Gear Geometry and Applied Theory. $2^{\text {nd }}$ ed., Cambridge University Press 2004.

- J. Phillips: General Spatial Involute Gearing. Springer Verlag, New York 2003.

- H. Pottmann, J. Wallner: Computational Line Geometry. Springer Verlag, Berlin, Heidelberg 2001.

- H. Stachel: Instantaneous spatial kinematics and the invariants of the axodes. Proc. Ball 2000 Symposium, Cambridge 2000, no. 23.

- H. Stachel: On Jack Phillips' Spatial Involute Gearing. Proc. $11^{\text {th }}$ ICGG, Guangzhou/P.R.China, 2004, pp. 43-48.

- H. Stachel: Teaching Spatial Kinematics for Mechanical Engineering Students. Proc. $5^{\text {th }}$ Aplimat, Bratislava 2006, Part I, pp. 201-209. 
- G.R. Veldkamp: On the Use of Dual Numbers, Vectors, and matrices in Instantaneous Spatial Kinematics. Mech. and Mach. Theory 11, 141-156 (1976).

- W. Wunderlich: Ebene Kinematik. Bibliographisches Institut, Mannheim 1970. 